\title{
Financial Restatements, Information Asymmetry, and Market Liquidity
}

\author{
Daewon $\mathrm{Kim}^{1}$ \& KwangJoo Koo ${ }^{2}$ \\ ${ }^{1}$ Assistant Professor, Dept. of Business Administration, College of Business, Keimyung University, Korea \\ ${ }^{2}$ Assistant Professor, Department of Accounting and Law, William Paterson University of New Jersey, Wayne, New \\ Jersey, USA \\ Correspondence: KwangJoo Koo, Department of Accounting and Law, Cotsakos College of Business, William \\ Paterson University, NJ, USA. Tel: 1-973-720-3871 E-mail: kook@wpunj.edu
}

Received: June 6, 2014

Accepted: July 28, 2014

Online Published: July 29, 2014

doi:10.5430/afr.v3n3p71

URL: http://dx.doi.org/10.5430/afr.v3n3p71

\begin{abstract}
This paper examine whether firms experience different liquidity effects from earnings restatements before and after the implementation of the Sarbanes-Oxley Act (SOX) by analyzing various measures of liquidity surrounding the announcement day in the period of 1997-2005. The study is based on the premise that SOX was intended to improve the transparency and reliability of reported information. We find that the spreads measured in cents detect an abnormality in liquidity due to a general downward trend in the spreads during the period. Dividing the period into three sub-periods because the SOX reinforce more accountability and more confidence for public financial information, we find virtually all declines in liquidity come from the pre-SOX period, which conversely explains that, no significant change in liquidity in the post-Sox period. Decrease in liquidity is influenced by restatements due to revenue recognition, those prompted by party other than auditors. The results show that firms experience more severe liquidity consequences following restatements announced before SOX. Therefore, information asymmetry should be less problematic, and liquidity should be less adversely affected, for restatements announced after SOX.
\end{abstract}

Keywords: Liquidity, Financial restatements, Information asymmetry, Disclosure, SOX

\section{Introduction}

In this paper, I examine the relationship between financial restatements encouraged by the Sarbanes-Oxley Act (SOX hereafter) and firms' liquidity. Specifically, this study analyzes market liquidity before and after the SOX to determine whether the Act and SEC rules improved the quality of public financial information and transparency of financial information, and thus reduced information asymmetries and increased liquidity. Our underlying hypothesis is that financial restatements enhance firms' liquidity, and thus firms provide more effective financial information to respond the information asymmetry.

In the aftermath of the corporate scandals (Enron, WorldCom, Qwest) and the recent financial crisis, all regulators and users raised serious concerns regarding the quality of financial information and transparency of public companies. Thus, the SOX influenced the most dramatic changes to U.S. public companies. These changes significantly contribute to capital market for disclosure requirements of U.S. public companies. Anecdotal evidence of Jain, Kim, and Rezaee (2008) provide that market liquidity improves after the enactment of SOX. Jain and Rezaee (2006), Li, Pincus, and Rego (2008), and Chhaochharia and Grinstein (2007) documented positive market reaction surrounding SOX.

The financial statements are an important source of information for investors with which they assess its performance and financial conditions. Regulators have used the impact of restatements on stock value (GAO, 2002). However, when public confidence in financial reporting is shaken, the effective functioning of the financial market is threatened. According to US Government Accountability Office (GAO), restatements have rendered billions of dollars of lost market capitalization, as markets react to news that companies make corrections on their prior financial statements or earnings reports. Thus, to improve disclosure requirements, public companies need to reduce the number of financial restatements to correct non-SOX and non-GAAP in issued financial statements. Anderson and Yohn (2002) and Palmrose, Richardson and Sholz (2004) show that the changes in absolute and relative quoted bid-ask spreads differ around restatement announcements. Palmrose et al. (2004) provide that the mean and dispersion of the earnings per share (EPS) forecasts of financial analysts decrease and increase, respectively, after restatement announcements. Hence, our arguments rest on the premise that differences in stock liquidity are determined by the extent of financial restatements after the introduction of SOX. 
The announcement of restatements provides an important opportunity to study how market responses to this critical financial event, as SOX claims to improve transparency, reliability, and accountability in listed firms. But, ever since the SOX, the effect of financial restatements for corporate overall liquidity has been unknown specifically. To the best of our knowledge, no study has provided comprehensive evidence of bid-ask spreads, depths, and adverse selection component of spreads as proxies for market liquidity around restatement announcements.

To address these issues, we empirically examine the market reaction by estimating liquidity measures on days surrounding a restatement announcement. This study covers the period from Jan, 1997 to Feb, 2005, which allows us to investigate the impact of the SOX Act of 2002 on liquidity of restating firms since the main goal of the Act is to enforce corporate accountability and to enhance the transparency of financial information. We find signs of inferior market liquidity, as evidenced by wider bid-ask spreads, lower depths, and higher adverse selection component of spreads after restatements announcements. This is consistent with our first hypothesis that financial restatements have a negative impact on the market liquidity measures. Our results also support the second hypothesis that market liquidity is pronounced in pre-Sox period than post-Sox period after restatements announcements. Liquidity decreases one day after restatement and remains at elevated levels 180 days after restatement. Therefore, liquidity is expected to worsen on these days as a restatement itself is an epitome of information asymmetry between investors and restating firm. These results show that the SOX reduce information asymmetry between investors and restating firm.

This study extends the literature of information quality by examining corporate liquidity for restating companies. Bhattacharya, Desai and Venkataraman (2013) find that accrual quality is positively associated with a corporate liquidity measure and that firms with poor earnings quality increase the number of financial restatements. This paper complements and extends the stream of research by focusing not on any single aspect of corporate liquidity, but on the overall effect of corporate liquidity for earning quality. In addition, this study also contributes to the liquidity literature for restating firms. Palmrose, Richardson and Sholz (2004), Anderson and Yohn (2002) provide the effects of financial restatements for trends in liquidity. Regulators would decrease the number of financial restatements to improve information quality through the SOX. This study is important for regulators who would know financial restatements affect firms' information environments after we include the SOX for the long period. Thus, this paper is the first to document that financial restatements worsen the overall liquidity of restating firms by considering their liquidity effect for much longer period.

Next, we perform an additional test to shed further light on the issue of liquidity on financial restatements. We also follow the Amihud (2002) measure of illiquidity, to verify that our results are robust to incorporating the effect of other unobservable performance measures. Taken together, we document that financial restatements are important drivers of corporate liquidity for information asymmetry.

Section 2 presents the developed hypotheses development and provides literature. Section 3 discusses the sample and the details of the empirical measures of corporate liquidities. Section 4 provides the empirical results and Section 5 presents the summary and conclusions.

\section{Literature review and hypotheses development}

\subsection{GAO report}

GAO issued a report, "Financial Statement Restatement: Trend, Market Impacts, Regulatory Responses, and Remaining Challenges" in both Oct 2002 and again in Oct 2006. The first report covers the period from Jan, 1997 to Jun, 2002, which will be referred to as the first period and the second from July, 2002 to Feb, 2005, referred to as the second period. In early 2002, the U.S stock market was fraught with companies involved in corporate scandals. For instance, many firms such as Xerox, Enron, and WorldCom restated their previous earnings in a magnitude of billions of dollars and erased investors' wealth and confidence significantly in the market. Since the first report, the GAO constructed and has been updating the database of publicly-traded firms that restate earnings in a year. GAO applied the following rule for identification and inclusion in the database: "announced restatements that were being made to correct previous material misstatements of financial results." More specifically these restatements represent accounting irregularities that were not fairly presented in accordance with generally accepted accounting principles (GAAP), including material errors and frauds. Hence, the firms reported in the sample represent a group of companies that made material corrections in their previous financial statements. Because of the relevance of the reports to this paper and its comprehensiveness in examining the impact of restatement on the market, we briefly summarize the major findings of the reports.

First, there's been an increasing trend in the number of restatements from 1997 to 2005 . The second report finds that 
the number of restatements grew by seven-fold from 1997 to 2002. One of the findings is a continued increase in the size of restating firms. While the average (median) size of market capitalization of these firms was $\$ 500$ million ( $\$ 143$ million) in 1997, the measures went up to \$10 billion (\$682 million). This phenomenon coincided with an increase in the number of the restating firms that are listed in major exchanges (NYSE, NASDAQ and AMEX). Second, the leading reason for restatement had been revenue recognition for the period from 1997 to 2002, while the second report finds that it was cost- or expense related. Third, internal parties such as the restating company's management or internal auditors prompted a majority of restatements, about $50 \%$ of restatements, in the both of the reports. Fourth, the three trading days surrounding the announcement date the stock prices of the restating firms dropped by about $10 \%$ during the first period, which resulted in an unadjusted $\$ 100$ billion loss ( $\$ 95.6$ billion loss in market-adjusted) in market capitalization. However, the loss in market capitalization significantly decreased for the second period, the second report documents a market-adjusted decrease of 1.9\% in stock price and $\$ 17.7$ billion and $\$ 36.5$ billion in market unadjusted and adjusted market capitalization. Fifth, revenue recognition continued to play a relatively dominant role in deteriorating market capitalization of the restating companies. But in the second period, the most severe market reaction was found in financial reporting fraud or other unspecified cause. The reports also looked at the intermediate-term effect of restatements, finding that in the intermediate term (60 days after the initial restatement) restating firms experienced on average an $18.2 \%$ and $1.7 \%$ decline in stock price and approximately an unadjusted \$240 billion loss and \$34 billion (\$126 billion loss when adjusted to market) gain in market capitalization respectively for the first and second period. This discrepancy in market reaction might suggest a change in the market participants' attitude toward restatements.

The second report offers three possible explanations for these different responses of the market: 1) positive overall market movement during 2003 to 2005, 2) an increase in perceived restatement and 3) grown insensitivity of the financial markets to restatement announcement since 2002. Finally, while in the first report financial restatements have general negative impacts on investor confidence, the impacts of them are inconclusive in the second report. In fact, the second report argues that the mixed confidence of investors comes from the fact that the financial markets are less certain about the driving force behind the increase in restatements. Citing analysts' comments, investors may have a difficulty in interpreting information conveyed by a restatement, for instance whether is due to "aggressive or abusive accounting practices, the complexity of accounting standards, the remediation of past accounting deficiencies, or just technical adjustments."

\subsection{Hypotheses development}

Restatements inform investors that the prior financial statements contain material errors which could affect firm value, and the perceived level of information asymmetry, and uncertainty about the quality of future financial statements (Callen, Livnat, \& Segal, 2006). Thus, many firms experience CEO turnover after financial restatements (Desai et al., 2006). Palmrose et al. (2004) examine the change of stock price after restatement announcements. They show that market reactions after restatements announcements are negative. Previous studies ( Kinney and Mcdaniel, 1989; Sennetti and Turner, 1999) show that firms with restatements tend to be smaller, less profitable, and have low growth than counterparts. These firms are likely to have a higher frequency of unqualified audit reports. Anderson and Yohn (2002) and Akhigbe, Kudla, and Madura (2005) provide the impact of financial restatements for liquidities. Thus, the findings of previous literature support the notion that outside investors reevaluate restated firms after restatements annoncements, and then the impact of reatatemtns will be negative in market liquidites.

The adverse impact of restatements brings information asymmetry. Anderson and Yohn (2002) find that information assymmertry increases after revenue recognition statements announcements. But, Wilson (2008) provides that the information asymmetry of earnings responses coefficient is temporary. Thus, restatements announcements tend to reduce the effect of poor earning quality in financial information instantly. Poor earning quality of financial information leads to information asymmetry, and then appears to reduce liquidity of firm stocks. Negative reaction to information asymmetry affects liquidity for all restatements. So, financial restatements result in the change of liquidity which the bid-ask spread widens to protect investors (Amihud and Mendelson, 1986; Leuz and Verrecchia, 2000).

Previous literature show changes in liquidity around financial restatements announcements. Palmrose et al. (2004) provide that there is no change in bid-ask spreads around restatement announcement. It also provides that the dispersion of analyst expectations increases around restatement announcement. Recently, Kryzanowski and Zhang (2010) find that relative quoted and effective spreads increase around restatement announcement. It also finds that Amihud's (2002) illiquidity estimates increase for revenue recognition restatements. They find that fraudulent restatements decrease liquidities. But, there is no paper to analyze long-term market liquidity upon financial 
restatments for investors. The focus of this study is to anlyyze the liquiditis for reducing financial restatements and information asymmetry.

Concerning specific market liquidity on financial event, Lee et al. (1993) study the dynamic relationship between bid-ask spread and bid-ask depth surrounding earning announcements, using the market data in 1998. They show that liquidity measured in the thirty-minute interval deteriorates (i.e. an increase in spreads and a decrease in depth) before earning announcements while spreads continue to widen for a trading day and depth reverts back to normal level within three hours after a release of earning. Jain et al. (2008) document that financial scandals in the early 2002 worsened market liquidity measured in quoted spreads, effective spreads for a short period. This study extends the work of Jain et al. (2008) by examining the possible market reaction to restatements during the pre-SOX period, during the financial scandal period and during the post-SOX period by using the five liquidity metrics: quoted, effective, percentage quoted, percentage effective spreads and depth.

Previous literature supports that outside investors can detect the quality of financial information throught financial restatemetns. The effects of restatemetns worsen information asymmetries. This leads investors to reevaluate their perceptions about information asymmetries of financial information of restated firms as well as the credibility of management of these firms. Thus, we expect that information asymmetries negatively affect market liquidity following the restatements announcement. These negative impacts of restatements can have adverse effects on market liquidity measures. Thus, following the timeline segmentation of the GAO reports and liquidity literature, this study proposes to investigate the following hypothesis on the effect of restatement on market liquidity. This leads to our first hypothesis:

H1: Financial restatements have a negative impact on the market liquidity measures over the period regardless the regulatory environment.

SOX intend to influence public companies' financial information credibility and investors in the capital markets (SOX, 2002; Forbes. 2002; Whitman, 2003). The changes in the informational environment such as SOX have different impact on firms depending on their firms' characteristics and corporate governance (Feroz, Park \& Pastena, 1991; Ribstein, 2002; La Porta, Lopez-De-Silanes, Shleifer, \& Vishny, 2002). Further examining the effect of SOX and SEC initiated rules, Jain et al. (2008) find significant improvement on market liquidity measures after the passage of SOX and the implementation of SEC rules. SOX would help to reduce information asymmetry of firms with the disclosure of financial restatements (Engel, Hayes \& Wang, 2007). A particular provision within SOX increased required information disclosures, which in turn reduced information asymmetry (Charles River Associates [CRA] International, 2005;CRA International, 2006 ). Chen, Cheng, and $\operatorname{Lo}(2014)$ also finds that the effects of information quality is diminished in the long-run after a restatement, because the effect of internal control weaknesses under Section 404 of SOX in affiliation with restatements is temporary. When sophisticated or informed investors reevaluate restating firms after SOX, the decrease in liquidity will be smaller. Thus, we expect that the effects of SOX on market liquidity will be different upon the SOX. We test whether SOX has reduced adverse selection problems in liquidity as below.

H2: SOX have reduced adverse selection problem that the negative effect of financial restatements is stronger for pre-SOX period than post-SOX period.

\section{Sample and Methodology}

\subsection{Sample}

The sample is populated by publicly-traded companies that announced restatement at least once in a given year from January 1, 1997 to September 30, 2005. The sample is collected from three separate reports published by GAO. Figure 1 shows the number of restatements in each year from January 1997 to September, 2005. It should be noted that some firms made more than one restatements in a particular year. So the number of restatements does not represent the number of restating firms. There is an apparent increasing pattern in the number of restatements. While it had been increased from 92 cases in 1997 to 225 in 2001, the increase was roughly doubled from 2002 reaching to 517 restatements at the end of Sept, 2005; in fact by the end of the year 2005, 647 restatements were recorded in GAO database. This increase in restatements after 2001 suggests that SOX requires stringent reporting standards on public companies. And firms faced more pressure to restate for errors of questionable materiality (Burks, 2011). The dataset also include the date of the restatement announcement, listing exchange of a restating firm, reason for restatement and initiating party of the restatement. All the firms here are listed on one of the following exchanges: NYSE, NASDAQ, or AMEX. I also collect additional information of financial restatements from the Lexis-Nexis and Factiva databases. 


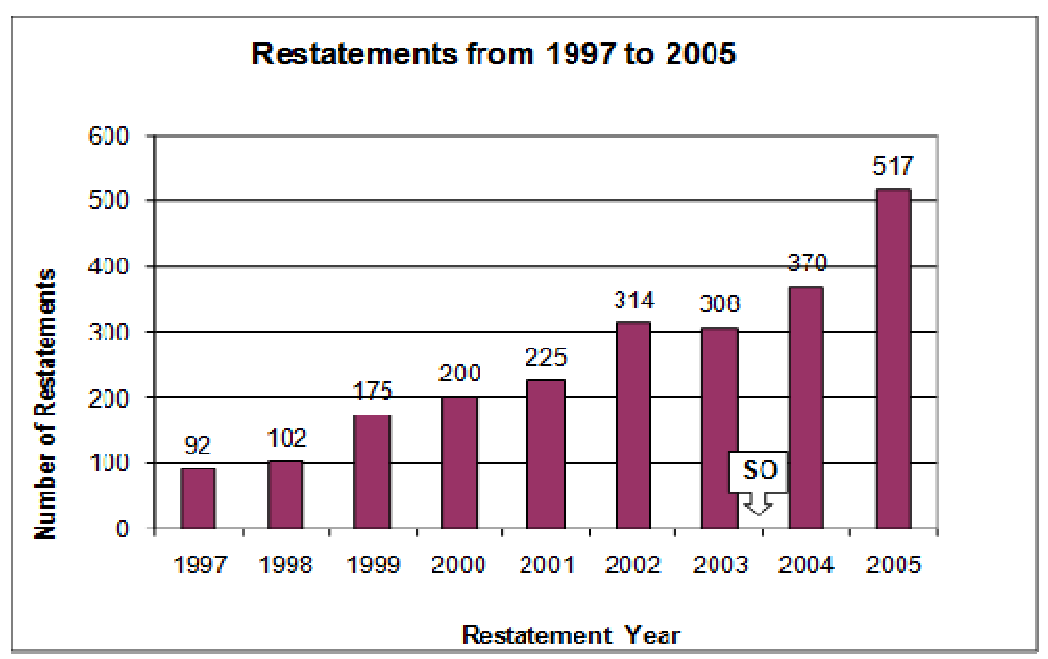

Figure 1. Number of restatements

Notes: The graph show the trend in number of firms that restarte publicly their previous financial result from Jan, 1997 to Feb, 2005. The number firms contain firms listed on NYSE, AMEX, and NASDAQ and firms traded over the counter.

Table 1 represents the breakdown of restatements according to their listings. For the entire period, the total number of restatement is 2,303 cases. The GAO report states that the average size of firms that restated earnings increased over this time period by five-fold (92 vs. 517). In a rough estimate, during the year 2005 approximately one out of every ten listed companies announced a restatement; an accelerated increase in the number of restating firms among listed firms is quite visible from Table 1. The dataset also includes reasons for restatements including cost or expense, mergers and acquisitions, in-progress research and development (IPRD), revenue recognition, securities related issues, related-party transactions, reclassification, restructuring assets, and inventory. Of 2303 restatements, the number of reasons was: 3 for 92 firms, 2 for 348 firms, and 1 for 1,864 firms.

Table 1. Sample description

\begin{tabular}{lccccccccc}
\hline & 1997 & 1998 & 1999 & 2000 & 2001 & 2002 & 2003 & 2004 & 2005 \\
Total & 92 & 102 & 175 & 200 & 225 & 314 & 308 & 370 & 517 \\
NYSE & 21 & 19 & 50 & 49 & 80 & 127 & 110 & 134 & 201 \\
Nasdaq & 61 & 66 & 99 & 116 & 113 & 148 & 132 & 150 & 218 \\
Amex & 2 & 11 & 9 & 10 & 8 & 14 & 23 & 40 & 42 \\
OTC & 8 & 6 & 17 & 25 & 24 & 25 & 43 & 46 & 56 \\
\hline \hline Listed* & 83 & 94 & 153 & 170 & 191 & 250 & 238 & 296 & 434 \\
Total listed** & 9275 & 9179 & 8739 & 8534 & 7902 & 7114 & 6780 & 6729 & 6473 \\
\% of listed firms & $0.89 \%$ & $1.02 \%$ & $1.75 \%$ & $1.99 \%$ & $2.42 \%$ & $3.51 \%$ & $3.51 \%$ & $4.40 \%$ & $6.70 \%$ \\
\hline
\end{tabular}

Notes: This table shows descriptive statistics for a sample of restating fims listed on corresponding exchange is repoted for the nine-year period from Jan, 1997 to Sep, 2005.*Listed include firms that announced restatement, counting only the first announcement in a particular year if it announced more than one restatement. ${ }^{* *}$ Total listed is the total number of firms listed on NYSE, NASDAQ, and AMEX.

To have reliable results in testing our hypotheses, we impose the following filters in selecting sample firms. First if a firm made more than one restatement in a year, only the first announcement day is kept. We also include only firms listed on NYSE, NSADAQ, and AMEX (.i.e. listed firms). The purpose of this filtering is to make the analysis comparable to the GAO reports, which studied only listed firms. The remaining firms are cross-checked with CRSP database and Compustat data to find if they exist in that database. The sample firms are required to have end-of-year data for market capitalization in CRSP; if a company made restatement in 1996, to be in the sample it must have market capitalization data in the end of previous year. This removes derivative securities like ADRs of foreign stocks, 
scores and primes (Amihud, 2002). After all the above filters, the sample consists of 1,765 firms out of the initial total restatements of 2303

For the calculation of liquidity measures, transaction data for the sample stocks, the quote date, time-stamp, ticker symbol, bid price, ask price, bid-depth, ask-depth, and exchange code are obtained from TAQ database(Trades and Quotes dataset released by the NYSE) at the Institute for the Study of Securities Markets (ISSM). Every transaction has the following information: a ticker symbol, time stamp, a transaction price or quoted prices (both bid and ask), the number of share traded for a trade or the number of shares at bid and at ask, and exchange code where the quote is originated. Because transaction data in TAQ include errors, standard filtering procedures in microstructure literature (e.g.,Huang and Stoll, 1996; 1997) are applied to retrieve only good quotes and trades. The procedures applied are as follows:

1) Eliminate quotes if the ask or the bid price is negative, if the spread is greater than $\$ 5$, and if the ask price is three times of the bid price.

2) Eliminate trades if the price or volume is negative.

3) Eliminate trades or quotes if they occur before the open of the market or after the close of the market and if they are out of sequence or include an error.

In addition to the filters above, we further require a stock to have at least two trades per day and have 100 trading days during the benchmark period. When we applied 200- and 150-trading-day filter, in both cases, a loss in the number of sample firm was significant. Moreover, because firms with no data on the event dates (day $-1,0$ and +1$)$ are eliminated as well, causing further loss in the number of sample firm, we set the trading-day requirement at 100 days. This requirement gives enough daily data for performing a t-test for difference in the mean for liquidity measures. After all the filtering process, the final sample includes 1,534 firms.

\subsection{Empirical Measures}

Following the methodologies of Jain et al. (2008), we employ the five liquidity measures and volume around the date of a restatement announcement. The five different liquidity measures are computed as follows:

$$
\begin{aligned}
& \text { Quoted spread }=\text { ask price }- \text { bid price } \\
& \text { Effective spread }=2 \times(\text { transaction price }- \text { quote midpoint }) \\
& \text { Percentage }(\text { proportional }) \text { quoted spread }=\text { quoted spread/quote midpoint } \\
& \text { Percentage (proportional) effective spread }=\text { effective spread } / \text { quote midpoint } \\
& \text { Depth }=\text { depth at ask }+ \text { depth at bid }
\end{aligned}
$$

The quoted spread and the depth are known to traders before each transaction, hence representing ex-ante cost of trading (Amihud and Mendelson, 1986; Brennan and Subrahmanyam,1998). In contrast, the effective spread measures the actual cost of a trading, usually reflecting that large number of trades occur within the quoted spread (Chorida et al, 2000). The larger the value of spreads, the more illiquid the stock is. But for depth, a large depth indicates better liquidity. Even though spreads and depth provide an intuitive inference about the direction of liquidity, inference of liquidity using either spread or depth in isolation might lead to ill-guided interpretation of market liquidity. Lee at al. (1993) argues that it is impossible to discern the direction of market liquidity with only quoted spread or depth. Only when spread and depth reinforce each other; an increase in depth is accompanied by a decline in spread, the inference is unequivocal. In addition, because of institutional constraint - maintaining acceptable level of spread and depth - imposed on the specialists, they use both spread and depth to manage liquidity risk. Therefore, there should be an empirical relation between the movement of spread and that of depth. Bacidore et al. (2002) discuss the deficiency of using spread or depth alone in measuring liquidity, introducing a depth improvement measure. They construct the composite measure of liquidity that addresses the deficiency of spread and depth and that can be useful if spreads and depth move into different directions. We use this measure to overcome problem in inferring liquidity direction with only either with spreads or depth. The measure is defined:

$($ Depth/Spread ratio $)=($ depth $/$ quoted spread $)$

Framing this research into an event study, the entire period is divided into the three sub-periods: the pre-event period, the event period, and the post-event period. The event period included five days in which day -2 and -1 and day +1 and +2 are two days before and after a firm announces restatement respectively. So day 0 is the very date when a firm announces a restatement. The pre-event period includes 248 trading days before day -2 . The benchmark for the liquidity measures are computed by averaging the cross-sectional daily averages of the measures of the sample firms during the pre-event period.

The grand mean of a liquidity measure is used as the hypothesized mean for the population of the sample firms. Then, 
for each day and for each liquidity measure in the event period, a t-test for the hypothesized sample mean (i.e. the grand mean) is implemented to test whether difference between a benchmark and the mean of an event day is statistically significant.

Table 2. Summary statistics of liquidity measures

\begin{tabular}{lccc}
\hline & Mean & Median & St \\
QSPRD (in cent) & 10.26 & 7.93 & 15.59 \\
RQSPRD (in \%) & 1.36 & 0.55 & 2.39 \\
ESPRD (in cent) & 8.34 & 6.41 & 12.13 \\
RESPRD (in \%) & 1.03 & 0.45 & 1.79 \\
DEP (in shares) & 5158 & 1764 & 13220 \\
DS-Ratio & 1375 & 243 & 9536 \\
Volume (in shares) & 879,511 & 161,800 & $3,143,489$ \\
Return (in \%) & -0.03 & 0 & 3.84
\end{tabular}

Notes: Summary statistics for the five liquidity measures including DS-ratio, volume, return are calculated for each sample firm with the daily data for the benchmark period of 248 days, then average through 1,534 firms. QSPRD stands for quoted spread, which is the difference between ask and bid price. RQSPRD is relative spread, which is the quoted spread divided by the quote midpoint ( ask + bid/2). ESPRD is the effective spread computed by subtracting quote midpoint from the trade price, then multiplying the computed value with 2 . RESPRD is relative( proportional) effective spread that is computed by diving the effective spread with the trade price. DEP is depth.

In Table 2, we present summary statistics for the five liquidity measures including DS ratio and volume, which are computed with the daily data for the benchmark period of 248 days by averaging through 1, 534 firms. For spreads, there is some right skewness, which is usually expected from distribution characteristics of the cross-section of daily average of spreads (Chordia, Richard, and Subrahmanyam, 2000). The mean and the median of the effective spread are smaller than those of the quoted spread, reflecting a large number of trades occur within the bid-ask spread. The mean and the median of depth are 5,158 and 1,764 shares respectively, indicating right-skewness in depth as well. Though DS ratio should be interpreted dynamically, on average an increase of one cent in the quoted spread would have a corresponding increase in depth of about 1,300 shares.

To examine the effect of SOX on liquidity for restating firms, the aggregated period starting from Jan, 1997 to Feb 2005 is broke up into the three segments: Pre-SOX period from Jan , 1997 to Feb, 2002, Financial scandal period from Mar, 2002 to July, 2002, and Post-Sox period from Aug, 2002 to Sept, 2005. For setting timeline of financial scandal period and Post-Sox period, we use the timeline setup of Jain et al (2008). In their study, the period of high profile financials scandal begins on March 11, 2002, ending Jun 26, 2002. The period after the scandal period and before Aug 1, 2002 is defined as period of congressional response. We combine these two periods because this period well represents an unusual market condition and the effect of Pre-SOX is fully absorbed into the market. For each of these periods, the same test for the aggregated period is performed. The results will reveal how market participants responded to restatement announcements under different regulatory regimes as well as under the deteriorated information asymmetry in which the confidence of market participants for the integrity of market were shaken due to restatement.

\section{Empirical analyses}

\subsection{Univariate Analysis}

We examine whether the mean of the five liquidity measures are statistically different from the benchmark values for the entire period in Table 3. The result completely supports the hypothesis of decline in liquidity in the days surrounding financial restatements in terms of the quoted and the effective spread. On average, these liquidity measures worsened during the event dates that span from day -2 to day +2 . In particular, there seem to be expected abnormalities (i.e., deterioration in measures) in the announcement day (day 0). Corresponding with deterioration in the spread and the depth, DS ratio also exhibits downturns. In addition, the percentage measures of spreads (RQSPR and RESPRD) give the same results from their counterpart of the quoted and the effective spread. While the means of the percentage measures of spread does not differ from the benchmark for intermediate and long-term effects, the percentage effective spread and the percentage of quoted spread are on average actually increased during the event dates, which reflects a worsening liquidity condition in the market.

To be consistent with the prediction of Easley and O'Hara (1992) that volume shocks are related with higher 
information risk and lower market liquidity, the percentage effective spread may genuinely reflect the liquidity condition of the sample firms during the event period. In addition, on average the restating firm experienced a decline of $-1.62 \%$ in return during the event dates, attesting the result of GAO reports. The deterioration in the spreads continues, represented by intermediate $(20$ trading days after day +2$)$ and long-term $(60$ trading days after day +2 ), while the percentage spreads revert back to the benchmark level.

Table 3. The results for the entire period ( Jun, $1997 \sim$ Sep, 2005)

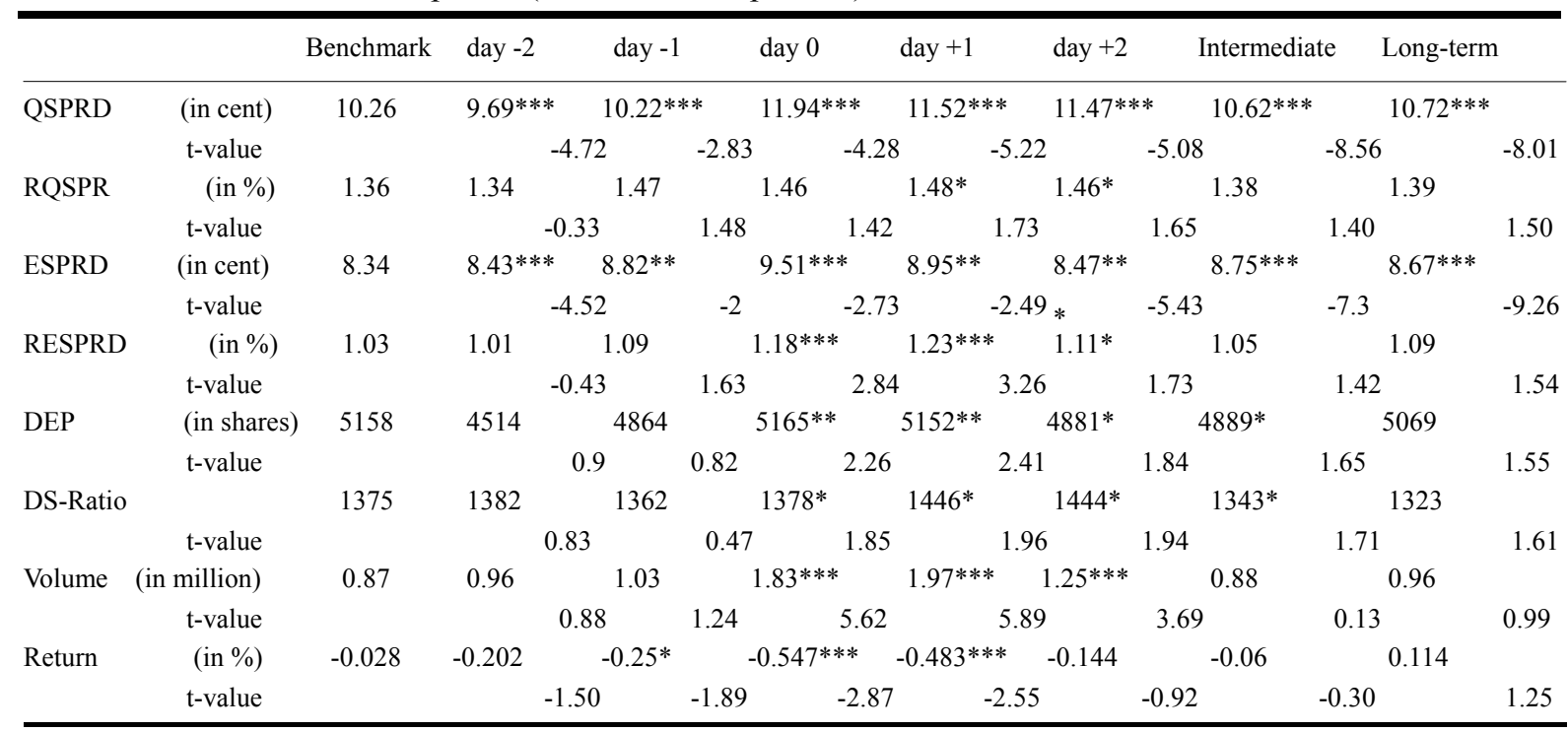

Notes: Each daily average level of liquidity is compared to the corresponding benchmark, which is computed with the data from the previous 248 trading days. Control variables are not reported in the table. The test determines whether the level of each measure differs significantly from the benchmark $* * * * *$, and $*$ indicates the level of significance at $99 \%, 95 \%$, and $90 \%$ respectively.

Table 4 reports the results of the t-test for the pre-SOX shown in panel A and post-Sox period in panel B. Comparing the values for the quoted spread from these two periods, apparently almost all portion of deterioration in the quoted spread comes from the sample firms in the pre-SOX period. In fact, any average values of quoted spreads during the event dates are statistically and significantly different from the benchmark. The supporting manifestation of deteriorations of the cent spreads and the percentage spreads also are still present. During the pre-SOX period the increase in all five liquidity measures are very pronounced surrounding the event dates, starting to rise on day -1 till day +2 . The statistically significant rise on day 1 might suggest an increased trading by the informed in advance of the announcement of restatement and the corresponding response of market makers by widening the bid-ask spread.

In general, during this period, a public disclosure of restatements offered an informational environment wherein its asymmetry among the market participants led to a negative impact on the market liquidity captured by the percentage spreads. We do not find any significant change in neither the percentage nor the cent spreads surrounding the event dates in the post-SOX period. Rather all spreads are worsened in the intermediate and in the long-term, which might reflect an enhanced trading condition for those restating firms that survived.

The distinguishable contrasting market reaction to restatement between the pre-SOX and the post-SOX period is quite striking. It is as if the informational effect carried by restatement has diminished to the degree to which the markets seem to consider not worth acting on. It probably attests the effect of SOX that the enactment of the law might have helped to mitigate information asymmetry in the market or as GAO cites that market participants has grown insensitive to the announcement of restatements, or the restatement itself might have opacity. Thus, the adverse movements in the liquidity measures, which are captured in the percentage spreads, but not in the cent spreads, are mostly attributed to the pre-Sox period. It also suggests more severe market reaction in this period, being consistent with the GAO findings about a $10 \%$ decline in stock price during the three trading days surrounding the announcement date.

Nevertheless, in the post-Sox period the volume shock is observed on day 0 and the ensuing two days after the announcement day as we see the pattern in the pre-Sox period. But for this period, the interpretation of the abnormally high volume of trading with the liquidity measure is rather difficult because there seems no inverse relation between the volume and any liquidity measures as predicted by Easley O'Hara (1992). Improving depth throughout the event dates in the pre-Sox period is rather perplexing while observing the deterioration in the 
percentage spreads. In the post-Sox period, depth remains almost constant from the benchmark period to the long-term though the increase on day 0 and day 1 are insignificant. It seems the increase in depth size surrounding the event dates correlates with the movement of volume. Additionally, it is the case where the inference of market liquidity direction is ambiguous as discussed in Lee et al (1993).

Table 4. The effects of SOX

Panel A. The test of the pre-SOX period (Jun, 1997 to Feb, 2002)

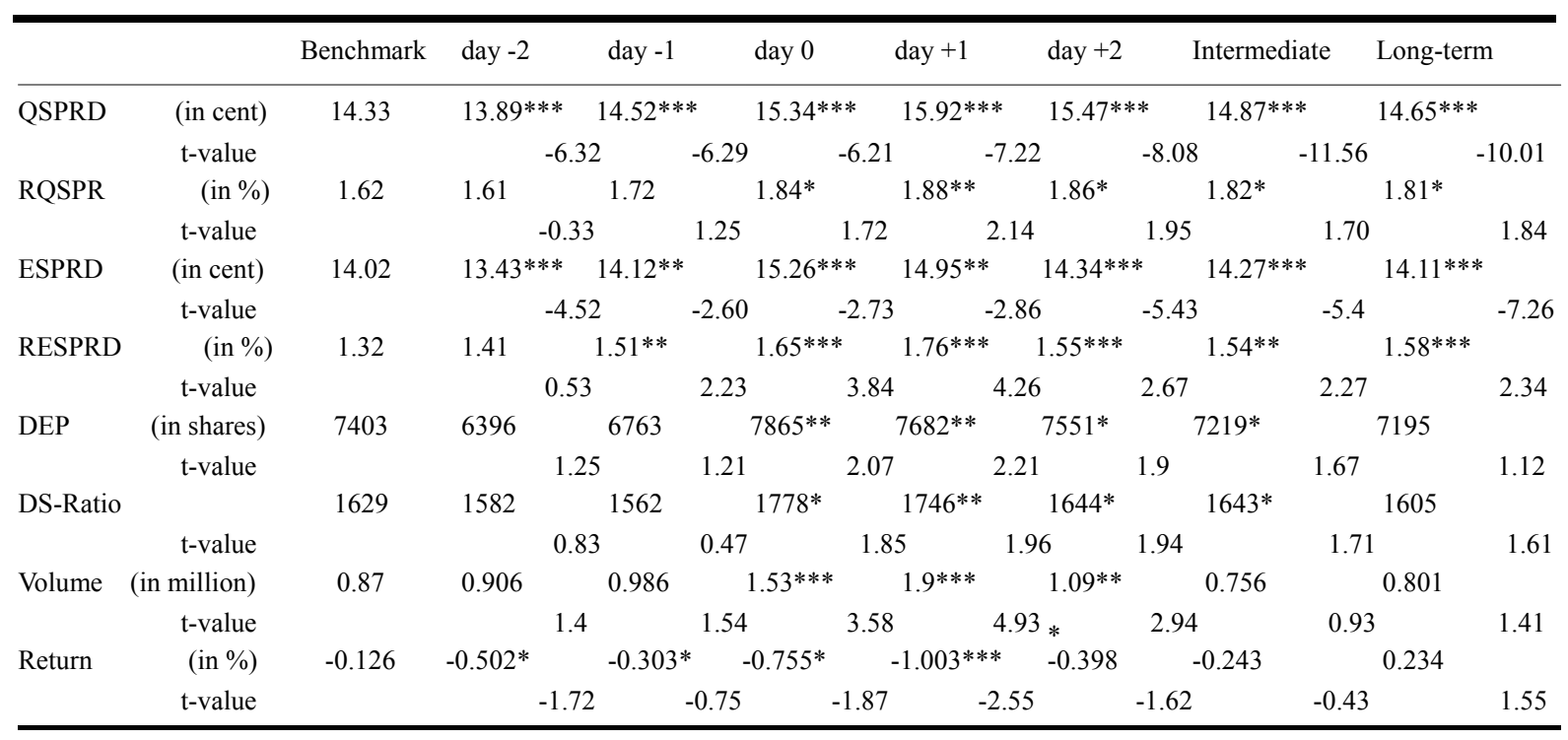

Panel B. The test of the post-SOX period( Aug, 2002 to Sep, 2005)

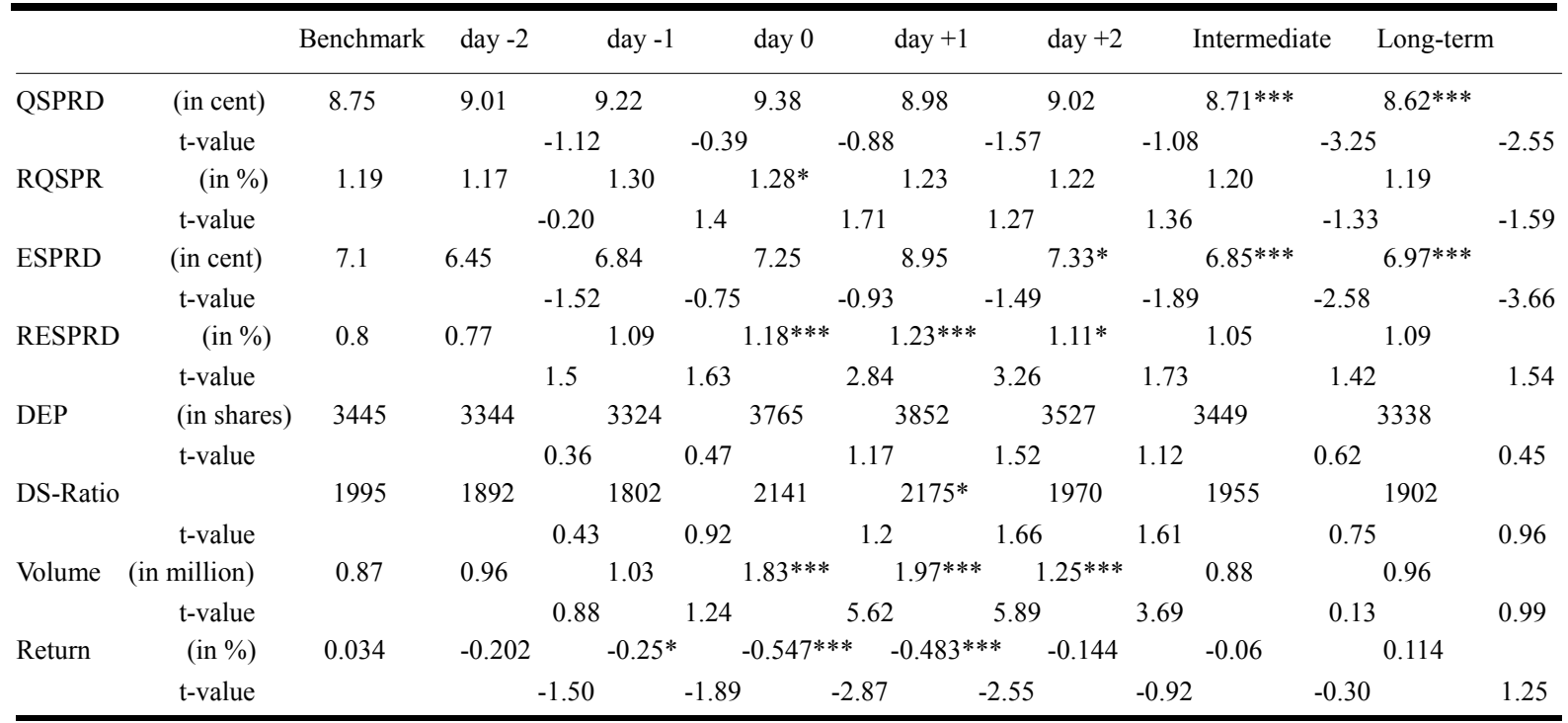

Notes: Each daily average level of liquidity is compared to the corresponding benchmark, which is computed with the data from the previous 248 trading days. Control variables are not reported in the table. The test determines whether the level of each measure differs significantly from the benchmark $* * *, * *$, and * indicates the level of significance at $99 \%, 95 \%$, and $90 \%$ respectively.

For the scandal period, due to the small sample size in the number of restating firms (about 40) and the extreme dispersion in depth and volume, the t-tests for them are unreliable; hence we do not report the result for them in Table. Only the results for spreads are presented in Table 5. Notice that the sample firms in this period actually experienced improvement in terms of the cent spread, while there were an adverse liquidity movement in the percent spreads, though not statistically significant. An improvement in intermediate and long term compared to the benchmark might imply a high level of information asymmetry before the announcement and subsequent abated informational environment after the announcement. 
Table 5. The test for the scandal period (from Mar, 2002 to July, 2002)

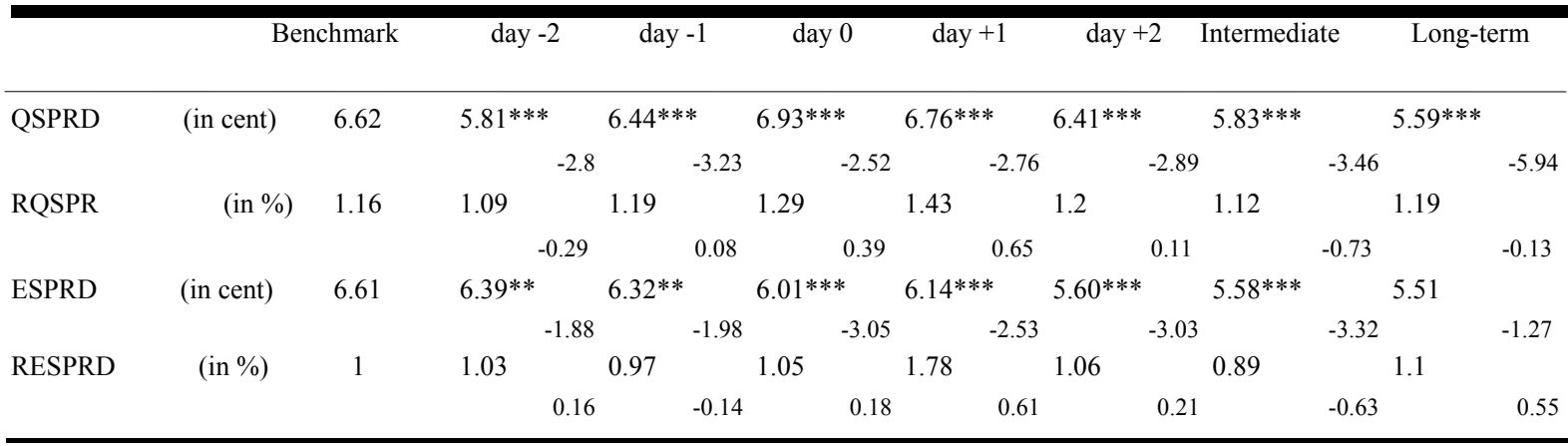

Notes: Each daily average level of liquidity is compared to the corresponding benchmark, which is computed with the data from the previous 248 trading days. Control variables are not reported in the table. The test determines whether the level of each measure differs significantly from benchmark $* * *$, **, and * indicates the level of significance at $99 \%, 95 \%$, and $90 \%$ respectively.

\subsection{Multivariate Analysis}

So far, our investigation of the impact of restatement on the liquidity measures has revealed the three major findings. First, the response of liquidity measures, especially in the proportional spreads to restatement, in the pre-SOX period differs from that of the post-SOX period. That is we observe deterioration in the proportional spreads (i.e. increase in the measures) in the former period. Second, there is a general decline of the spreads in cents during the both period. Third, unfavorable price movements, negative returns, are a general phenomenon whether it is the pre-SOX or the post-SOX. But the degree of adverse movements is greater in the former than latter period supporting for the hypothesis 2 .

Given these findings, we extend our analysis to examine whether the corrosion of the proportional spread can explain the cumulative abnormal return days surrounding the announcement of restatement. To answer the proposed question, we follow the method of Jain and Kim (2006). In their study, they attempt to answer a question with the effect of announcements of exchange switching, but in our case it is the announcement of restatements. We estimate the following simultaneous system of equations:

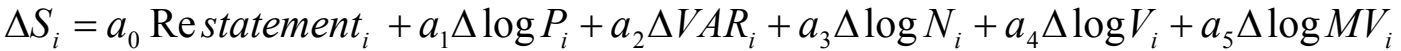

$$
\begin{aligned}
& C A R_{i}=b_{0}+b_{1} \Delta S_{i}
\end{aligned}
$$

In essence, for equation (6) we use the well-known trading-cost regression model, which shows the relation between the spread and a firm's trading characteristics, developed by Stoll (2000). For our purpose that is how the changed trading characteristics of a restating firm impact on the spread, we take a change in values in the each variable. The intercept is labeled as restatement to capture the effect of restatement after controlling for the other variables. The subscript $\mathrm{i}$ indicates a sample company. $\Delta \mathrm{Si}$ is the change in the proportional quoted spread as the dependent variable. Before taking the difference in each variable except MV, we first compute a 20-trading-day average for the time window ( -22 to -3$)$ and $(+3$ to +22$)$; the missing period $(-2$ to +2$)$ is used for computing cumulative abnormal return, CARi. Then we get differences by subtracting values of the former window from those of the latter window. For MV, the market capitalization at the end of the previous year and that at the end of the current year, that is the year a sample firm made a restatement, is used to measure change in the market capitalization. In equation (7), the expected returns for the individual sample stock is measured by using the estimates of the CAPM model with the data for a 248-day window from -250 to -3 :

$$
R_{i t}=\alpha_{i}+\beta_{i} R_{m t}
$$

where Rit and Rmt are the return of a sample stock and the market on day t. We use S\&P 1500 return as a proxy for the daily market return. With the estimated value of and, we compute the expected returns of the stocks during the event window $(-2,0)$. By subtracting the expected returns from the daily raw returns and sum the daily differences, we derive the abnormal return (CARi) for stock $\mathrm{i}$.

Finally, we implement a two-stage least square estimation approach by first obtaining the estimated value of $\Delta \mathrm{Si}$, with the actual values of the independent variables, then using this expected value as an endogenous variable in equation (7). The use of the predicted values of change in the proportional quoted spread is that investors cannot foresee perfectly the magnitude of deterioration in the spread. Thus this will show how the expected decline in liquidity affects the abnormal returns during the event-window 
In Table 6, we present the result of the simultaneous system of equation with which we investigate the effect of worsened liquidity on stock return around the day of restatement announcement. Because of the differential degree of liquidity decline between in the sample firms in the pre-SOX period and in the post-Sox period, we also report the result of the system for these period in column 3 and 5 in addition to column 1 where the result for the entire period is presented. We have the supporting result regarding the effect of restatement on the change in the spread. In column 3 , we find a positive value of the intercept, which is relatively larger and hence more salient, shows up in the pre-SOX period. But, the intercept in the pre-SOX is positive and negative in the post-SOX, leading to the completely support for our hypotheses. In the both period, the change in price has an adverse effect on the change in spread; assuming relatively lower price after restatement, it worsens liquidity by increasing the change in the spread. The impact of price on the spread is much stronger in the pre-SOX than the post-SOX period. The coefficient of trading activity, dollar volume in the pre-SOX and number of trades in the post-Sox, also suggests that a decrease in the activity results in liquidity deterioration. In sum, we find that the change in price and the change in trading activity, considering that both of them show a negative value, is the main determinant of deterioration in liquidity.

In panel $\mathrm{B}$, we present the estimates of the CAR equation by plugging in the expected value of the change in the spread from equation (7). In panel B, negative changes in the spread seem to affect the abnormal return, suggesting additional return over the market. Furthermore, the magnitude of the coefficient on the estimated value of the spread in the pre-Sox is about twice greater than that in the post-SOX, which implies the abnormal return in the pre-Sox is much responsive to the change in the predicted spread.

In general, univariate analysis and multivariate analysis suggests that liquidity is reduced after restatements annoucemtns. Information asymmetry initiated by financial restatements is diminished in the long-run. The changes in the informational environment, SOX, could help to reduce information asymmertry between informed investors and uninformed investors, and then the negative effect of financial restatements is smaller for post-SOX period than pre-SOX period.

Table 6. The results of 2SLS

Panel A. Dependent variable is $\Delta \mathrm{S}$

\begin{tabular}{ccccccc}
\hline \multirow{2}{*}{ Variable } & \multicolumn{2}{c}{ Entire Period } & \multicolumn{2}{c}{ Pre-Sox } & \multicolumn{2}{c}{ Post-Sox } \\
\cline { 2 - 7 } Intercept & Estimate & t-Value & Estimate & t-Value & Estimate & t-Value \\
(Restatement) & -0.011 & -0.460 & 0.071 & 3.080 & -0.064 & -2.110 \\
$\Delta \mathrm{P}$ & -0.804 & -8.390 & -0.976 & -7.223 & -0.420 & -2.120 \\
$\Delta \mathrm{VAR}$ & 1.059 & 1.790 & -2.170 & -0.380 & 1.133 & 4.910 \\
$\Delta \mathrm{N}$ & -0.281 & -2.640 & 0.041 & 0.280 & -0.320 & -4.740 \\
$\Delta \mathrm{V}$ & -0.048 & -0.600 & -0.221 & -1.520 & 0.140 & 1.100 \\
$\Delta \mathrm{MV}$ & 0.003 & 0.080 & -0.008 & -0.180 & -0.001 & -0.020 \\
Adj_Rsquare & 0.156 & & 0.226 & & 0.193 & \\
\hline
\end{tabular}

Panel B. Dependent variable is $\triangle \mathrm{CAR}$

\begin{tabular}{ccccccc} 
& \multicolumn{2}{c}{ Entire Period } & \multicolumn{2}{c}{ Pre-Sox } & \multicolumn{2}{c}{ Post-Sox } \\
\cline { 2 - 7 } Variable & Estimate & t-Value & Estimate & t-Value & Estimate & t-Value \\
\hline Intercept & -0.001 & -0.340 & 0.004 & 0.780 & 0.002 & 0.660 \\
$\Delta S$ & 0.125 & 12.070 & -0.091 & 8.340 & -0.049 & 6.330 \\
Adj_Rsquare & 0.115 & & 0.136 & & 0.054 &
\end{tabular}

Notes: Panel shows the estimated values of the coefficient for computing the predicted value of the change in the spread, which in turn is used as the independent variable in Panel B. Each variable in Panel A is a difference between the averages of daily data for twenty-day before and after the announcement (i.e. subtracting the former mean from the latter mean). $\Delta \mathrm{P}, \Delta \mathrm{VAR}, \Delta \mathrm{N}, \Delta \mathrm{V}$, and $\Delta \mathrm{MV}$ are a change in daily average price, in return variance, in number of trades, in dollar volume, and market capitalization respectively. Control variables are not reported in the table.

To test the robustness issues of the separation of the sample period, we separated into the two segments: pre-SOX and post-SOX. For each of these periods, the same test for the aggregated period is performed. The results don't be changed. 


\section{Conclusion}

This study investigates the impact of restatements on market liquidity. We separately examine maket reaction by estimating five liquidity measures on days surrounding a restatement announcement from Jan, 1997 to Feb, 2000. During the entire period, we find that the quoted and effective spread, liquidity measures in cents, detect the deteriorating condition of liquidity on days after the announcement of restatement. We find that financial restatements have a negative impact on the market liquidity measures over the period. Inferior market liquidity, as evidenced by wider bid-ask spreads, lower depths, and higher adverse selection component of spreads after restatements announcements is worsen. This is consistent with our first hypothesis that financial restatements have a negative impact on the market liquidity measures. Nonetheless, the percentage effective spread is able to detect abnormality in liquidity on the day of restatement. We also find that the volume is abnormally high on the announcement day and the following two days.

To answer our research questions, we segment the entire period into the pre-Sox, the scandal, and the post-SOX. We find that most of the enhancement in the spreads comes from the pre-SOX period, yet both proportional quoted and effective spread significantly worsened during the event period. Interestingly, these measures do not revert back to the benchmark level after 60 trading days in the pre-Sox period. In addition, the cent spreads deteriorates for the entire period, especially experiencing more precipitous decline in the pre-SOX period.

During the post-SOX, neither the cents nor percent spreads exhibit any statistically significant abnormality, indicating virtually no market reaction to the restatement announcement. But, we find an abnormal level of volume on the announcement day and the ensuing two days. Our results support that an decrease of market liquidity is pronounced in pre-Sox period than post-Sox period after restatements announcements. This apparent change in the attitude toward restatement in the post-Sox period might be attributed to perceived changes in market environment such as improved transparency after the enactment of SOX, increased complexity in information delivered by restatement due to stringent reporting requirements of SOX. This leads Information asymmetry between investors and restating firm to improve through the good information environment.

\section{Acknowledgements}

The authors would like to thank the editor and the two anonymous referrers for their helpful comments and suggestions.

\section{References}

Akhigbe, A., Kudla, R.J. \& Madura, J. (2005). Why are some corporate earnings restatements more damaging. Applied Financial Economics ,15, 327-336. http://dx.doi.org/10.1080/0960310042000338722

Amihud, Y., \& Mendelson, H. (1986). Asset pricing and the bid-ask spread. Journal of Financial Economics ,17, 223-249. http://dx.doi.org/10.1016/0304-405X(86)90065-6

Amihud, Y. (2002). Illiquidity and stock returns: cross-section and time series effects. Journal of Financial Markets,5, 31-56. http://dx.doi.org/10.1016/S1386-4181(01)00024-6

Anderson, K.L., \& Yohn, T.L. (2002). The effect of 10-K restatements on firm value, information asymmetries, and investors' reliance on earnings. Working Paper, Georgetown University.

Bacidore, J., Battalio, R. \& Jennings, R. (2002). Depth improvement and adjusted price improvement on the New York Stock Exchange. Journal of Financial Markets, 5, 169-195. http://dx.doi.org/10.1016/S1386-4181(01)00026-X

Bhattacharya, N., Desai, H. \& Venkataraman, K. (2013). Earnings Quality and Information Asymmetry: Evidence from Trading Costs. Contemporary Accounting Research, 30, 482-516. http://dx.doi.org/10.1111/j.1911-3846.2012.01161.x

Brennan, M. J., \& Subrahmanyam, A. (1998) . The determinants of average trade size. Journal of Business, 71, 1-25. http://dx.doi.org/10.1086/209734

Burks, J. (2011 ). Are Investors Confused by Restatements after Sarbanes-Oxley?. The Accounting Review, 86 (2), 507-539. http://dx.doi.org/10.2308/accr.00000017

Callen, J., Livnat, J., \& Segal, D.( 2006) .Accounting Restatements: Are They Always Bad News for Investors. The Journal of Investing ,15, 57-68. http://dx.doi.org/10.3905/joi.2006.650145

Charles River Associates (CRA) International. (2005). Sarbanes-Oxley Section 404 Costs and Implementation Issues: Survey Update: Washington, DC (December 8).

Charles River Associates (CRA) International. (2006). Sarbanes-Oxley Section 404 Costs and Implementation Issues: Spring 2006 Survey Update. Available at:http://www.crai.com/

Chen, X., Cheng, Q., \& Lo, A. (2014). Is the Decline in the Information Content of Earnings Following Restatement 
Short-Lived? The Accounting Review, 89(1), 177-207. http://dx.doi.org/10.2308/accr-50594

Chhaochharia, V. \& Grinstein , Y. (2007) . Corporate Governance and Firm Value: The Impact of the 2002 Governance Rules, Journal of Finance, 62 (4), 1789-1825.

Chordia, T., Richard, R., \& Subrahmanyam, A. (2000). Commonality in Liquidity. Journal of Financial Economics, 56, 3-28. http://dx.doi.org/10.1016/S0304-405X(99)00057-4

Desai, H., C. E. Hogan, \& M. S. Wilkins.(2006). The reputational penalty for aggressive accounting: Earnings restatements and management turnover. The Accounting Review, 81, 83-112. http://dx.doi.org/10.2308/accr.2006.81.1.83

Easley, D., \& O'Hara, M. (1992). Time and the Process of Security Price Adjustment. Journal of Finance , 47, 577-605. http://dx.doi.org/10.1111/j.1540-6261.1992.tb04402.x

Engel,E., Hayes, R., \& Wang, X. (2007). The Sarbanes-Oxley Act and firms' going-private decisions. Journal of Accounting and Economics, 44, 116-145. http://dx.doi.org/10.1016/j.jacceco.2006.07.002

Feroz, E., Park, K., \& Pastena. V. (1991). The Financial And Market Effects Of The SEC's Accounting And Auditing Enforcement Releases. Journal of Accounting Research, 29 , 107-142. http://dx.doi.org/10.2307/2491006

Forbes. 2002. The corporate scandal sheet. http://www.forbes.com/home/2002/07/25/accountingtracker.html.

GAO (United States Government Accountability Office). Financial Restatement: Trends,Market, Impacts, Regulatory Responses, and the Remaining Challenges Oct 2002 and 2005, http://www.gao.gov/new.items/d03138.pdf, http://www.gao.gov/new.items/d06678.pdf.

Huang, R., \& Stoll, H.(1996). Dealer versus auction markets. Journal of Financial Economics, 41, 313-357. http://dx.doi.org/10.1016/0304-405X(95)00867-E

Huang, R., \& Stoll, H. (1997). The components of the bid-ask spread: A general approach. Review of Financial Studies, 10, 995-1034. http://dx.doi.org/10.1093/rfs/10.4.995

Jain, P., Kim, J., \& Rexaee, Z.(2008). The Sarbanes-Oxley Act of 2002 and Market Liquidity. The Financial Review, 43, 361-382. http://dx.doi.org/10.1111/j.1540-6288.2008.00198.x

Jain, P., \& Kim, J. (2006). Investor recognition, liquidity, and exchange listings in the reformed markets. Financial management, 35 (2), 21-42. http://dx.doi.org/10.1111/j.1755-053X.2006.tb00140.x

Kinney, R.W., \& McDaniel, L.S. (1998). Characteristics of firms correcting previously reported quarterly earnings. Journal of Accounting \& Economics, 11, 71-93. http://dx.doi.org/10.1016/0165-4101(89)90014-1

Kryzanowski, L. \& Zhang, Y. (2010). Corporate event risk: canadian financial restatements. Working Paper.

La Porta, R., Lopez-De-Silanes, F.,Shleifer, A., \& Vishny, R. (2002). Investor protection and corporate valuation. Journal of Finance, 57, 1147-1170. http://dx.doi.org/10.1111/1540-6261.00457

Lee, C., Mucklow, B., \& Ready, M. (1993). Spreads, Depths, and the Impact of Earnings Information: An Interday Analysis. Review of Financial Studies, 2, 345-374. http://dx.doi.org/10.1093/rfs/6.2.345

Leuz, C., \& Verrecchia, R. (2000). The economic consequences of increased disclosure. Journal of Accounting Research, 38, 91-124. http://dx.doi.org/10.2307/2672910

Li, H., Pincus, M., \& Olhoft Rego, S. (2008). Market Reaction to Events Surrounding the Sarbanes Oxley Act of 2002 and Earnings Management. Journal of Law \& Economics, 51 (1), 111-134. http://dx.doi.org/10.1086/588597

Palmrose, Z., Richardson, V., \& Scholtz, S. (2004). Determinants of Market Reactions to Restatement Announcements. Journal of Accounting and Economics, 37, 59-89. http://dx.doi.org/10.1016/j.jacceco.2003.06.003

Ribstein, L. ( 2002). Market vs. regulatory responses to corporate fraud: A critique of the Sarbanes-Oxley Act of 2002. Journal of Corporation Law, October 1

Sarbanes-Oxley Act of 2002. The Public Company Accounting Reform and Investor Protection Act. http://www.whitehouse.gov/infocus/corporateresponsibility. (H.R. 3763).

Sennetti, J., \& Turner, J. (1999). Post-audit restatement risk and brand-name audits. Working Paper, Nova Southeastern University.

Stoll, R. (2000). Friction. Journal of Finance, 4, 1479-1514. http://dx.doi.org/10.1111/0022-1082.00259

Whitman, J. (2003). Sarbanes-Oxley begins to take hold, Wall Street Journal. (March 25), C9.

Wilson, W. (2008). An empirical analysis of the decline in the information content of earnings following restatements. The Accounting Review, 83, 519-549. http://dx.doi.org/10.2308/accr.2008.83.2.519 